\title{
Assessment of Glutathione Level in Non-Alcoholic Fatty Liver Disease Patients
}

\author{
Y. Pavan Kumar Reddy ${ }^{\circledR 1}$, Suraj Uppalapati ${ }^{\circledR 2}$ \\ ${ }^{1}$ Associate Professor, Department of Gastroenterology, Sapthagiri Institute of Medical Sciences and Research Center, Bangalore, Karnataka, India, ${ }^{2}$ Assistant Professor, \\ Department of Gastroenterology, Sapthagiri Institute of Medical Sciences and Research Center, Bangalore, Karnataka, India.
}

\section{Abstract}

Background: Non-alcoholic fatty liver disease (NAFLD) is a range of hepatic disorders associated with fatty deposits in liver, which occur in the absence of alcohol consumption or alcohol abuse. NAFLD. The present study assessed glutathione level in non-alcoholic fatty liver disease patients. Subjects and Methods: The present study was conducted in Department of Internal Medicine, Narayana Medical College \& Hospital, Chintareddy Palem, Nellore, Andhra Pradesh. Duration of the study was from February 2018 to January 2019. 40 patients of NAFLD and 20 cases of fatty liver disease were recruited. Serum levels of 8-OHdG were measured using the highly sensitive 8-OHdG Check enzyme-linked immunosorbent assay (ELISA). Serum levels of GGT were measured using the Qualigent ${ }^{(B}$ GGT kit. Serum levels of glutathione (GSH) were measured using the GSH kit. Results: The mean total bilirubin in group I was $1.2 \mathrm{mg} / \mathrm{dL}$ and in group II was $0.7 \mathrm{mg} / \mathrm{dL}$, aspartate transaminase was $58.2 \mathrm{U} / 1$ in group I and $62.6 \mathrm{U} / 1$ in group II, alanine transaminase in group I was $142.4 \mathrm{U} / 1$ in group I and 128.2 U/1 in group II, alkaline phosphatase was 284.2 U/1 in group I and 302.4 U/1 in group II and $\gamma$-glutamyltranspeptidase in group I was $98.2 \mathrm{U} / 1$ and $118.4 \mathrm{U} / 1$ in group II. The difference was non- significant $(\mathrm{P}>0.05)$. The mean glutathione level in group I was 0.6 and in group II was 0.4 and which increased to 1.4 in group I and 1.2 in group II after 3 months. The difference within the group found to be significant $(\mathrm{P}<0.05)$. Conclusion: Authors found that there was reduction in alanine transaminase, glutathione and gamma-glutamyltranspeptidase level. Antioxidant therapy with glutathione may reduce the pathological oxidative stress in the liver in NASH, preventing the progression from NAFLD to NASH cases.

Keywords: Alanine Transaminase, Fatty Liver, Glutathione

Corresponding Author: Suraj Uppalapati, Assistant Professor, Department of Gastroenterology, Sapthagiri Institute of Medical Sciences and Research Center, Bangalore, Karnataka, India.

E-mail: drsurajuppalapati@gmail.com

Received: 12 February 2020

Revised: 14 March 2020

Accepted: 23 March 2020

Published: 18 May 2020

\section{Introduction}

The presence of a significant ( $>5 \%$ of hepatocytes) fat accumulation in the liver, in the absence of an "unsafe" quantity of alcohol consumption and any other cause of liver diseases, is a potentially pathological condition that is defined as nonalcoholic fatty liver disease (NAFLD).

Non-alcoholic fatty liver disease (NAFLD) is a range of hepatic disorders associated with fatty deposits in liver, which occur in the absence of alcohol consumption or alcohol abuse. NAFLD begins with an initial stage of fatty liver also known as hepatic steatosis. ${ }^{[1]}$ The progression from steatosis into cirrhosis of the liver due to inflammation and fibrosis results in irreversible damage to the liver. This condition is called nonalcoholic steatohepatitis (NASH) - a term first introduced by Ludwig et al. in clinical subjects with no history of alcohol consumption or abuse. ${ }^{[2]}$
In oxidative stress, the serum level of oxidized glutathione increases and hepatic GGT is induced; this then dismantles the oxidized glutathione and converts it to reduced glutathione. ${ }^{[3]}$ Gammaglutamyltranspeptidase, therefore, has an important role in antioxidant defense systems at the cellular level and is a valuable marker of oxidative stress in NAFLD. ${ }^{[4]}$ It has been reported that levels of GGT in FL patients may compensate for mild oxidative stress by repressing 8-OHdG levels and preventing progression to NASH; oxidative stress leads to increased levels of 8-OHdG and the development of NASH. It may also contribute to clinical progression from simple FL to NASH. ${ }^{[5]}$ The present study assessed glutathione level in non-alcoholic fatty liver disease patients. 


\section{Subjects and Methods}

The present study was conducted in Department of Internal Medicine, Narayana Medical College \& Hospital, ChintareddyPalem, Nellore, Andhra Pradesh. Duration of the study was from February 2018 to January 2019. 40 patients of NAFLD and 20 cases of fatty liver disease. All patients were informed regarding the study and written consent was obtained. Ethical approval was obtained from institute prior to the study.

Patient data such as name, age, gender etc. was recorded. A through clinical examination was performed. Serum levels of 8-OHdG were measured using the highly sensitive 8OHdG Check enzyme-linked immunosorbent assay (ELISA) kit according to the manufacturer's instructions. Serum levels of GGT were measured using the Qualigent ${ }^{\circledR}$ GGT kit. Serum levels of glutathione (GSH) were measured using the GSH kit. Results thus obtained were subjected to statistical analysis. P value less than 0.05 was considered significant.

Results

Table 1: Distribution of patients

\begin{tabular}{|lll|}
\hline Total- 60 & Group I (FLD) & $\begin{array}{l}\text { Group } \\
\text { (NAFLD) }\end{array}$ \\
\hline Number & 40 & 20 \\
\hline
\end{tabular}

Table 1 shows that patients were divided into 2 groups. It consisted of 20 cases of fatty liver disease in group I and 40 patients of NAFLD in group II.

\begin{tabular}{|c|c|c|c|}
\hline Groups & $\begin{array}{l}\text { Group } \\
\text { I (FLD) }\end{array}$ & $\begin{array}{l}\text { Group II } \\
\text { (NAFLD) }\end{array}$ & $P$ value \\
\hline $\begin{array}{l}\text { Total biliru- } \\
\text { bin }(\mathrm{mg} / \mathrm{dL})\end{array}$ & 1.2 & 0.7 & 0.82 \\
\hline $\begin{array}{l}\text { Aspartate } \\
\text { transaminase } \\
(\mathrm{U} / \mathrm{l})\end{array}$ & 58.2 & 62.6 & 0.13 \\
\hline $\begin{array}{l}\text { Alanine } \\
\text { transaminase } \\
(\mathrm{U} / \mathrm{l})\end{array}$ & 142.4 & 128.2 & 0.17 \\
\hline $\begin{array}{l}\text { Alkaline } \\
\text { phosphatase } \\
\text { (U/l) }\end{array}$ & 284.2 & 302.4 & 0.21 \\
\hline $\begin{array}{l}\gamma- \\
\text { Glutamyltransp } \\
(\mathrm{U} / \mathrm{l})\end{array}$ & 98.2 & 118.4 & 0.71 \\
\hline
\end{tabular}

\begin{tabular}{|c|c|c|c|}
\hline $\begin{array}{l}\text { Glutathione } \\
\text { levels }\end{array}$ & $\begin{array}{l}\text { Group } \\
\text { I (FLD) }\end{array}$ & $\begin{array}{l}\text { Group II } \\
\text { NAFLD) }\end{array}$ & P value \\
\hline Before & 0.6 & 0.4 & 0.52 \\
\hline $\begin{array}{l}\text { After } \\
\text { months }\end{array}$ & 1.4 & 1.2 & 0.71 \\
\hline$P$ value & 0.01 & 0.01 & NA \\
\hline
\end{tabular}

*NA (Not Applicable)

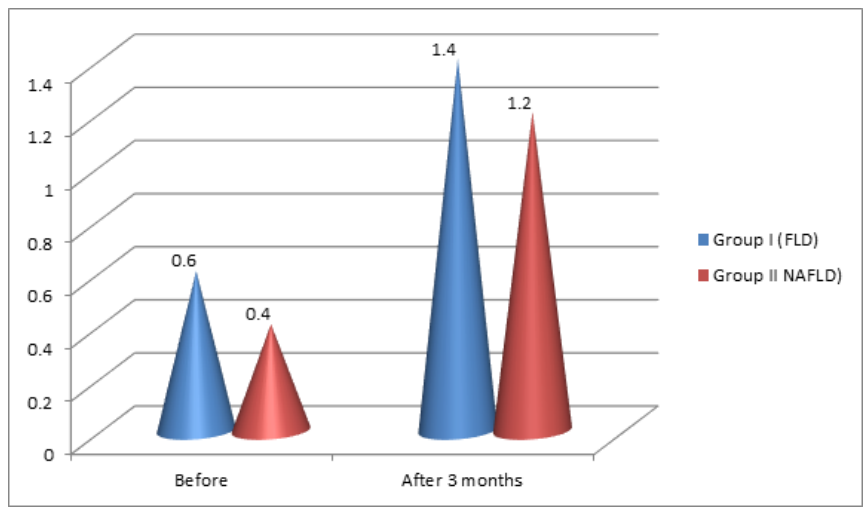

Figure 1: Serum glutathione levels in both groups

\begin{tabular}{|cllll|}
\hline \multicolumn{5}{|c|}{ Table 4: Comparison of parameters in both groups } \\
\hline Groups & Period & Group I & Group II & P value \\
\hline Alanine & Before & 142.4 & 128.2 & 0.17 \\
\hline \multirow{2}{*}{ - } & 3 months & 130.2 & 120.6 & 0.12 \\
\hline \multirow{2}{*}{} & Before & 102.8 & 104.6 & 0.14 \\
\hline & 3 months & 98.4 & 94.2 & 0.11 \\
\hline & Before & 98.2 & 118.4 & 0.71 \\
\hline
\end{tabular}

Table 2 shows that mean total bilirubin in group I was 1.2 $\mathrm{mg} / \mathrm{dL}$ and in group II was $0.7 \mathrm{mg} / \mathrm{dL}$, aspartate transaminase was $58.2 \mathrm{U} / 1$ in group I and $62.6 \mathrm{U} / 1$ in group II, alanine transaminase in group I was $142.4 \mathrm{U} / 1$ in group I and 128.2 $\mathrm{U} / 1$ in group II, alkaline phosphatase was $284.2 \mathrm{U} / 1$ in group I and $302.4 \mathrm{U} / 1$ in group II and $\gamma$-glutamyltranspeptidase in group I was $98.2 \mathrm{U} / 1$ and $118.4 \mathrm{U} / /$ in group II. The difference was non- significant $(\mathrm{P}>0.05)$.

Table $3 \&$ Figure 1 shows that mean glutathione level in group I was 0.6 and in group II was 0.4 and which increased to 1.4 in group I and 1.2 in group II after 3 months. The difference within the group found to be significant $(\mathrm{P}<0.05)$.

Table $4 \&$ Figure 2 shows that there was reduction in value of alanine transaminase, 8-hydroxy-2-deoxyguanosine and $\gamma$ glutamyltranspeptidase in both groups after 3 months. 


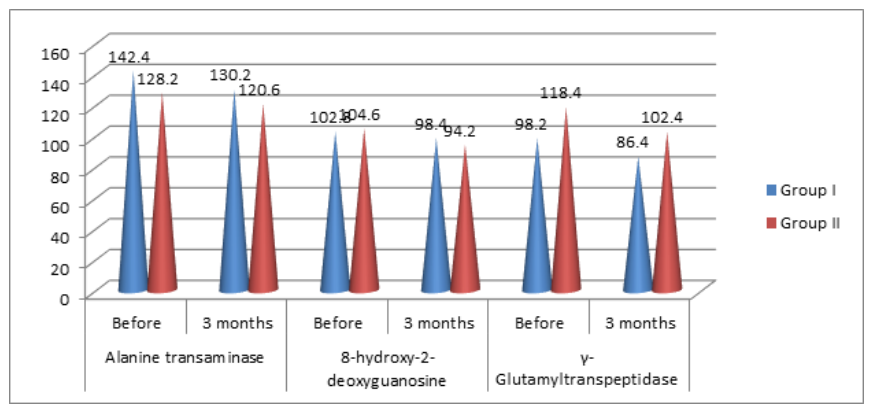

Figure 2: Comparison of parameters in both groups

\section{Discussion}

The prevalence of NAFLD is estimated to be as high as $17-33 \%$ in the general population, while it reaches $75 \%$ in obese individuals and even more in patients with type 2 diabetes mellitus (T2DM). ${ }^{[6]}$ The concomitant presence of T2DM increases the risk of progression of liver damage and constitutes a significant risk for cardiovascular diseases. Although obesity, particularly central (abdominal) obesity, is a well-recognized risk factor for it, NAFLD has been also reported in lean individuals (body mass index $<30$ $\left.\mathrm{kg} / \mathrm{m}^{2}\right) .{ }^{[7]}$ Furthermore, the prevalence of NAFLD differs depending on the gender, ethnicity, and race as a proof of probable involvement of genetic and epigenetic factors in the pathogenesis of the disease. Insulin resistance (IR) is the major pathophysiological factor implicated in NAFLD, as well as metabolic syndrome (MS), a cluster of cardiovascular risk factors comprising visceral obesity, blood hypertension, glucose intolerance, and dyslipidemia. In this way, NAFLD has been considered as the liver expression of MS, not only burdened with high cardiovascular risk but also responsible of a progressive metabolic, cardiovascular, and/or kidney disease, even without an overt MS. ${ }^{[8]}$ The present study assessed glutathione level in non-alcoholic fatty liver disease patients.

In present study, patients were divided into 2 groups. It consisted of 20 cases of fatty liver disease in group I and 40 patients of NAFLD in group II. Irie et al, ${ }^{[9]}$ evaluated whether an antioxidant agent, glutathione, prevents the development of NASH from FL. Five patients with FL and 10 with NASH were enrolled in the study. Three hundred milligrams per day of glutathione was given orally to patients with nonalcoholic fatty liver disease (NAFLD) every day, and an oxidative stress marker and biochemical tests were analyzed before treatment and 1 and 3 months after starting the treatment. They measured serum levels of 8-hydroxy2-deoxyguanosine (8$\mathrm{OHdG}$ ) and gamma-glutamyltranspeptidase (GGT). Immunohistochemistry for glutathione was performed on formalin fixed liver specimens obtained from liver biopsies. Before treatment, the NASH group had higher serum $8-\mathrm{OHdG}$ and lower serum glutathione levels than the FL group. Immunohistochemistry revealed that a strong expression of glutathione was observed in zone 3 in both NASH and FL before treatment. Serum levels of alanine transaminase and $8-\mathrm{OHdG}$ were significantly decreased after treatment in the NASH group. Gamma-glutamyltranspeptidase was decreased after treatment, although the decrease was statistically not significant.

We found that mean total bilirubin in group I was 1.2 $\mathrm{mg} / \mathrm{dL}$ and in group II was $0.7 \mathrm{mg} / \mathrm{dL}$, aspartate transaminase was $58.2 \mathrm{U} / 1$ in group I and $62.6 \mathrm{U} / 1$ in group II, alanine transaminase in group I was $142.4 \mathrm{U} / 1$ in group I and $128.2 \mathrm{U} / 1$ in group II, alkaline phosphatase was $284.2 \mathrm{U} / 1$ in group I and $302.4 \mathrm{U} / 1$ in group II and $\gamma$-glutamyltranspeptidase in group I was $98.2 \mathrm{U} / 1$ and $118.4 \mathrm{U} / /$ in group II. The mean glutathione level in group I was 0.6 and in group II was 0.4 and which increased to 1.4 in group I and 1.2 in group II after 3 months.

The pathophysiology of NASH was originally explained by the "two-hit" hypothesis. In this hypothesis, the first hit is responsible for producing steatosis (fat accumulation in liver), and the second hit is from oxidative stress causing lipid peroxidation. ${ }^{[10]}$ The pathogenesis and progression of NAFLD is complex, and was not completely explained by the "two hit" hypothesis. Currently, NASH is described by the "multiple hit" hypothesis. In this hypothesis, metabolic syndrome plays a major role due to insulin resistance and the inflammatory process mediated by interaction of different proteins and immune system. The components of the multiple "hits" are yet to be fully defined and they may vary in different patients. ${ }^{[11]}$ However, from available information, the "first hit" is caused by metabolic syndrome and insulin resistance, increased fat loading in hepatocytes leading to steatosis and liver injury. The accumulation of fat in the liver occur as a result of imbalance between the rate of influx and removal of triglycerides a mechanism thought to protect hepatocytes from the lipotoxicity that may result from excessive influx of free fatty acids (FFAs). ${ }^{[12]}$

\section{Conclusion}

Authors found that there was reduction in alanine transaminase, glutathione and gamma-glutamyltranspeptidase level. Antioxidant therapy with glutathione may reduce the pathological oxidative stress in the liver in NASH, preventing the progression from NAFLD to NASH cases.

\section{References}

1. Fabbrini E, Sullivan S, Klein S. Obesity and nonalcoholic fatty liver disease: Biochemical, metabolic, and clinical implications. Hepatol. 2010;51(2):679-689. Available from: https: //dx.doi.org/10.1002/hep.23280. 
2. Gaggini M, Morelli M, Buzzigoli E, DeFronzo R, Bugianesi E, Gastaldelli A. Non-Alcoholic Fatty Liver Disease (NAFLD) and Its Connection with Insulin Resistance, Dyslipidemia, Atherosclerosis and Coronary Heart Disease. Nutrients. 2013;5(5):1544-1560. Available from: https://dx.doi.org/10. 3390/nu5051544.

3. Wagner LBV, Rinella ME. The role of insulin-sensitizing agents in the treatment of nonalcoholic steatohepatitis. Ther Adv Gastroenterol. 2011;4(4):249-263. Available from: https: //dx.doi.org/10.1177/1756283x11403809.

4. Krawczyk M, Bonfrate L, Portincasa P. Nonalcoholic fatty liver disease. Best Pract Res Clin Gastroenterol. 2010;24(5):695708. Available from: https://dx.doi.org/10.1016/j.bpg.2010.08. 005 .

5. Floyd RA, West MS, Eneff KL, Hogsett WE, Tingey DT. Hydroxyl free radical mediated formation of 8hydroxyguanine in isolated DNA. Arch Biochem Biophys. 1988;262(1):266-272. Available from: https://dx.doi.org/10. 1016/0003-9861(88)90188-9.

6. Ore A, Akinloye OA. Oxidative Stress and Antioxidant Biomarkers in Clinical and Experimental Models of NonAlcoholic Fatty Liver Disease. Medicina. 2019;55(2):26-26. Available from: https://dx.doi.org/10.3390/medicina55020026.

7. Ota T, Takamura T, Kurita S, Matsuzawa N, Kita Y, Uno $\mathrm{M}$, et al. Insulin Resistance Accelerates a Dietary Rat Model of Nonalcoholic Steatohepatitis. Gastroenterology. 2007;132(1):282-293. Available from: https://dx.doi.org/10. 1053/j.gastro.2006.10.014.

8. Rolo AP, Teodoro JS, Palmeira CM. Role of oxidative stress in the pathogenesis of nonalcoholic steatohepatitis. Free Radic Biol Med. 2012;52:59-69. Available from: https://dx.doi.org/ 10.1016/j.freeradbiomed.2011.10.003.

9. Irie M, Sohda T, Anan A, Fukunaga A, Takata K, Tanaka T. Reduced Glutathione suppresses Oxidative Stress inNonalcoholic Fatty Liver Disease. Euroasian J Hepatogastroenterol. 2016;6(1):13-18. Available from: https://dx.doi.org/10.5005/ jp-journals-10018-1159.

10. Masarone M, Rosato V, Dallio M, Gravina AG, Aglitti A, Loguercio C, et al. Role of Oxidative Stress in Pathophysiology of Nonalcoholic Fatty Liver Disease. Oxid Med Cell Longev. 2018;2018:9547613-9547613. Available from: https://dx.doi. org/10.1155/2018/9547613.

11. Day CP, James OFW. Steatohepatitis: A tale of two "hits"? Gastroenterol. 1998;114(4):842-845. Available from: https: //dx.doi.org/10.1016/s0016-5085(98)70599-2.

12. Angulo P. Nonalcoholic Fatty Liver Disease. N Eng J Med. 2002;346(16):1221-1231. Available from: https://dx.doi.org/ 10.1056/nejmra011775.

Copyright: (C) the author(s), 2020. It is an open-access article distributed under the terms of the Creative Commons Attribution License (CC BY 4.0), which permits authors to retain ownership of the copyright for their content, and allow anyone to download, reuse, reprint, modify, distribute and/or copy the content as long as the original authors and source are cited.

How to cite this article: Reddy YPK, Uppalapati S. Assessment of Glutathione Level in Non-Alcoholic Fatty Liver Disease Patients. Acad. J Med. 2020;3(1):19-22.

DOI: dx.doi.org/10.47008/ajm.2020.3.1.5

Source of Support: Nil, Conflict of Interest: None declared. 